\title{
Learning through an Innovative Formative Assessment Strategy: An Ex- ploratory Study of How Engineering Students Interpret System Equilibrium
}

\author{
Ms. Sensen Li, Purdue University, West Lafayette \\ Dr. Sean P Brophy, Purdue University, West Lafayette
}

Dr. Sean Brophy is an Associate Professor in the School of Engineering Education at Purdue University. His research in engineering education and learning sciences explores how undergraduate engineering students think and reason with models as they engage in design and troubleshooting problems. At the core of this work is defining students' ability to think and reason at a systems level. This work has potential to inform instructors on approached to helping engineering students transfer what they know to novel situations. 


\title{
Learning through an Innovative Formative Assessment Strategy: An Exploratory Study of How Engineering Students Interpret Buoyancy
}

\begin{abstract}
Engineering students usually generate diagrams to offload memory and information processing when they design and analyze systems. It is challenging for instructors to provide formative assessment and feedback on their diagrams and systematically and rapidly diagnosing their conceptions of a situation. This study introduces an innovative instructional method, called "pseudo peer diagram" (PPD), where students compare and contrast their work with others as a formative feedback mechanism. Fourteen students who graduated from the First Year Engineering Honors Program were asked to generate free body diagrams to interpret equilibrium in the provided systems. PPDs were presented to enable a direct comparison and to serve a metacognitive function for students who use them as feedback to practice and build up their own self-check strategies. In order to understand how individuals cognitively process PPDs, this study used think-aloud protocol to make students' cognition explicit.

This study revealed several challenges that students encountered when they used free body diagrams to interpret system equilibrium. This study also indicates the effectiveness of PPDs in externalizing students' understanding of system equilibrium. This research is relevant to engineering instructors and researchers who want to develop students' abilities to use cognitive strategies effectively. It may also interest engineering instructors who are willing to apply new instructional methods and tools to facilitate students to overcome complex design challenges.
\end{abstract}

\section{Theory}

Effective formative assessment process has repercussions on all aspects of students' learning ${ }^{[1],[2]}$. It can help students understand marking criteria and subject standards ${ }^{[3]}$, produce significant learning gains, and eventually raise academic standards in classrooms ${ }^{44]}$. Instead of treating formative assessment as a particular "test", formative assessment should be regarded as a process that involves collecting evidence about how students make progress during learning and making necessary instructional adjustment to facilitate their progress ${ }^{[5]}$. As long as the assessment is specifically intended to generate feedback on performance to improve learning, it is formative ${ }^{[6]}$. Therefore, understanding how students think in the learning process, especially how they respond to feedback, increases the effectiveness of formative assessment.

As a critical component of formative assessment, effective feedback has drawn much attention from researchers ${ }^{\left[{ }^{[1,},[6]\right.}$. Researchers indicated that when students were involved in difficult tasks, immediate feedback could make them feel safe; yet when students were involved in simple tasks, delayed feedback might provide opportunities for them to reflect ${ }^{[7]}$. Moreno and Mayer further explained the reason from a cognitive load perspective ${ }^{[8]}$. They suggested that, by providing feedback immediately after students 
made an attempt in the problem solving process, they could easily make meaningful connections between the feedback and their answers because both pieces of information were simultaneously being held in their working memory. However, even when feedback was immediate, simply giving students the correct answer might only promote the rote recall of knowledge ${ }^{[9]}$. Additional elaborations, such as asking students to explain their thinking ${ }^{[10]}$, presented indicators to teachers to diagnose students' challenges and encouraged active construction of knowledge ${ }^{[11]}$. It is important for instructors to notice that feedback should satisfy students' current levels of understanding ${ }^{[12]}$. After systematic practice and use of formative assessment, the quantity of details of feedback could be reduced to a minimal level ${ }^{[13]}$. Therefore, students themselves have to actively process information and learn to develop the skill of analyzing their own work. To facilitate complex feedback situations, Hmelo-Silver \& Barrows identified following strategies: asking open-ended questions, encouraging explanations to clarify and legitimize ideas, comparing and contrasting by using visual representations and generating and evaluating hypotheses ${ }^{[14]}$. These effective strategies can be adapted to multiple domains and be applied in different learning contexts.

Though its educational importance is generally acknowledged, traditional approaches to engineering education are limited in their potential for formative assessment ${ }^{[15]}$. The interaction between engineering instructors and students can be abstracted and described as 'sender-receiver' model, which fails to highlight students' reasoning processes ${ }^{\text {[16] }}$. Yet a pressing goal of engineering education today is acquiring knowledge to perform various actions, like design, troubleshooting and analysis ${ }^{[17]}$. To satisfy this goal, we need effective assessments capable of telling us in details about how students cognitively approach engineering concepts and unpack problems.

One way to provide formative assessment is to use graphical representations. As we know, engineers and engineering students usually generate visual representations to offload memory and information processing when they design and analyze systems. Their abilities to interpret and illustrate others' representations are also important to the communication of ideas. Visual representations can provide unique information beyond what textual descriptions can provide ${ }^{[18]}$. If the representations are confusing, it may hinder students' understanding towards the concept conveyed since they need to figure out the manner in which it is represented before interpreting the concept. In addition, Gieskes, DeRusso, \& McGrann pointed out that representations used in engineering education, especially in mechanical engineering, have great effect on students' analytical methods when they encounter similar concepts ${ }^{[19]}$.

\section{Model}

Much of the engineering learning and knowledge is represented in diagrams, which makes feedback provision a challenge because it is difficult to gather students' results and to provide meaningful information. This study attempted to overcome this challenge by presenting a pre-designed diagram and relying on self-check strategies and studentstudent interactions. Different from personal response systems, this study didn't share a particular student's diagram in public, but presented a "pseudo peer" diagram designed 
by the instructor. The use of "pseudo peer" can avoid students' uneasiness caused by the work being criticized and judged by peers. Similar to other graphical representation tools, PPDs can support structural and functional inferences of an engineering system using mental transformations, mental scanning, etc. ${ }^{[20]}$. Students with an incorrect solution already have some understanding of the task, therefore, their readiness to interpret PPDs enhances their awareness of errors and facilitates the problem solving process ${ }^{21]}$.

This study proposed two types of pseudo peer diagrams, i.e., normal peer diagram and super peer diagram. Frequently, a pseudo peer diagram (PPD) is a completed diagram with all of the anticipated components and relationships explicitly stated. It can be generated by combining common methods used by prior students. However, in some situations, instructors may want to include some common errors in the diagrams, and expect students to identify these errors. This kind of diagrams is called normal peer diagram. Different from normal peer diagram, super peer diagram covers a comprehensive version of knowledge that instructors expect students to learn, and the chosen examples are typical of designated levels of competence. Instead of being regarded as "standards", these examples are indicative of standards in an implicit way ${ }^{[6]}$.

Providing PPDs during problem solving process enables a direct comparison and encourages students to focus on generating a general plan or sequence of principle applications that can be followed in order to solve the problem. Compare-and-contrast strategy highlights similarities and differences between two diagrams. Successful applications of this strategy include training students in writing ${ }^{\text {[2] }}$ and reading ${ }^{[23]}$. It can help students cognitively perform the act of classification, distinguish between types of ideas, and facilitate the formation and attainment of conceptual and metacognitive knowledge ${ }^{[24]}$. It can also support students making connections by "identifying and learning key concepts and networks of information" ${ }^{25]}$. Research on using compare-andcontrast strategy in students writing process indicated that students are able to transfer the structures of compare-and contrast to other areas, such as planning, use of resources and organization of ideas ${ }^{[26]}$. It can also raise instructors' awareness of how student learning occurs and the context they create ${ }^{[27]}$.

Another critical educational need that PPDs satisfy is that it helps instructors to train students in how to interpret feedback, how to make connections between their work and the feedback, and how to improve their own work ${ }^{[6]}$. Asking "what-if" question is one of the effective strategies to provide formative feedback because it can elicit students' thinking to consider different scenarios ${ }^{[28]}$. For example, instructor could take PPD as an example, and ask students "what would the system change if this component was added?" Therefore, it can facilitate students noticing what kinds of questions they need to ask as well as increase students' potential for insight toward interesting alternatives to a problem.

\section{Context}

First-year engineering students had some prior knowledge in science gained from high school and daily life. Some of the knowledge provides good background information for 
them to interpret new knowledge, but other prior conception may not be compatible with the currently accepted knowledge and they are referred to as "misconception" [29] Streveler et al. argued that some misconceptions are more "robust" than others in engineering context, e.g., thermal science and electric circuits ${ }^{[30]}$. They further cited Chi's work to explain the theories behind this, i.e. these "robust" misconception usually have "emergent" phenomena indirectly caused by the underlying physical processes, in which the causal connections as well as the associated function are difficult to identify ${ }^{[31]}$.

In this study, the authors chose "buoyancy" as the context to set up the experiment. Even though sinking and floating is not a strange phenomenon to students, there are many basic misconceptions that contribute to confusion regarding this topic, such as size, shape, density, texture of an object ${ }^{[32], \text { [33] }}$. Different from previous studies, this paper focused on undergraduate students' analysis of forces, e.g. gravity, buoyancy, and tension using free body diagrams. As first year engineering students, they are expected to consider buoyancy as the resultant pressing force exerted by the fluid on everybody immersed in it [34]. They are also expected to apply the appropriate formula to the prediction of relevant phenomena and explanation of engineering systems.

One way to overcome the misconception and to interpret system equilibrium is to use free body diagrams to unpack the system. Free body diagrams are a common visual representations used in engineering education. This diagram illustrates forces acting on the body of interest. The primary use of a free-body diagram is to allow the student to treat the body as a stand-alone element in a simplified shape drawn around the center of gravity. All interactions with other components of the system are illustrated only as forces ${ }^{[35]}$. Previous studies on how first year engineering students generate and interpret free body diagrams indicated that students have troubles in assigning the correct reactions to specific forces and they can make great improvement once they practice with multiple problems ${ }^{[36]}$. Studies on using an automatic feedback system to facilitate students' construction of free body diagram indicated that students request more detailed feedback and extensive diagnostics when they construct a free body diagram ${ }^{[36]}$. One effective method to provoke productive thoughts is to ask questions like "which body exerts the force that you have drawn on that free body diagram?" or "Precisely what bodies from the original system are you including in your free body diagram?" [37] These questions lead students to think about the fundamental concepts while they generate free body diagrams.

In this study, the authors is interested in exploring 1) how students generate free body diagrams to interpret system equilibrium; 2) how students compare and contrast the given normal peer diagrams to their own solution; 3) how students compare and contrast the given super peer diagrams to their own solution; and 4) how students apply the strategies they identified in the super peer diagrams (if applicable) to refine the normal peer diagrams as well as their own initial solutions. Specifically, the research questions in this study are:

1. What challenges do engineering undergraduate students encounter when they generate free body diagrams to interpret system equilibrium? 
2. How do engineering undergraduate students compare their work with pseudo peer diagrams and revise their own diagrams?

\section{Methodologies}

\section{Participants}

The participants in this study were 14 students who graduated from an honors version of the first year engineering (FYE) course at a large middle west university. These students self-selected into the course and were accepted on a first come basis. Usually they had a strong academic background and were highly motivated to achieve academically. In addition, they were well trained in using free-body diagrams to interpret different engineering systems. Participants were recruited by a mass email sent to students who completed the course in the past two years. Interviews were arranged on a first come first come bases. Each participant received \$15 gift certificates from a site like Amazon.com for their one hour work.

\section{Task}

As illustrated in Figure One, a fishing hook is stuck by stones in a river. Attached to the fishing hook is a float. Students were asked to generate a free body diagram to illustrate the forces acting on the float. Then they were asked to predict the movements of the fishing float by answering "what if the thread is cut, what would happen to the float?" They were also expected to generate a free body diagram to explain their thinking. Finally, they were asked to justify if there is any change to the buoyancy acting on the fishing float from the initial state, to the middle state and to the final state.

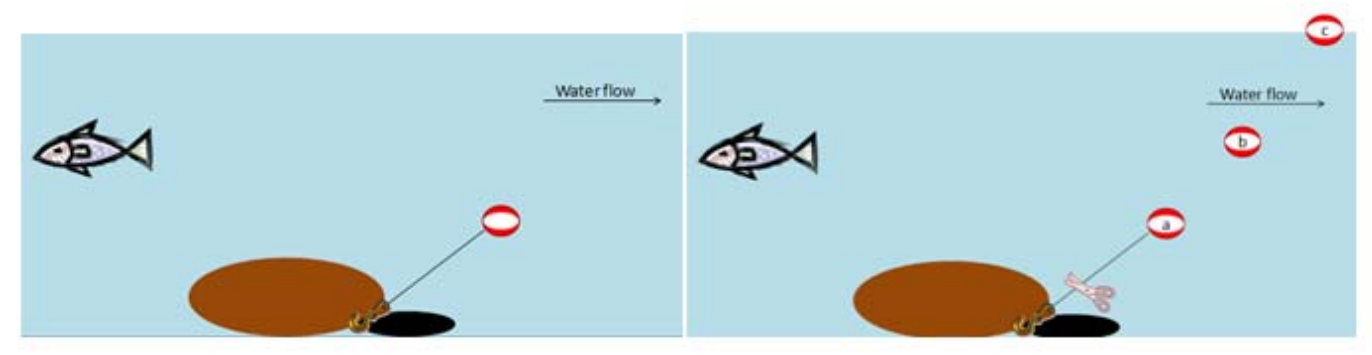

Figure One, Fishing Float Scenario

Procedure

Think-aloud protocol was used to track students' progressive interpretations and understanding of buoyancy. This method allowed students to perform the task with minimum interruptions from the experimenter (other than providing them with the worksheet on request). Students were asked to justify their responses and explain certain reported "observations" in the scenario. Engagement with the scenario created a context that allowed examining students' reasoning in some depth. Such examination was 
achieved through further probing by providing two pre-designed PPDs (normal peer diagram and super peer diagram respectively) for students to compare and contrast with.

In order to get students ready for comparison with PPDs, there were asked to generate their own free body diagrams to interpret the system first. Then they were asked to compare and contrast the given normal peer diagram and super peer diagram with their own diagram. Students were expected to apply the strategies they identified from the super peer (if applicable) to solve the problems of the normal peer. An information sheet with basic knowledge on buoyancy was provided, and students could access it anytime in the problem solving process. In other words, there was no tailored feedback provided in order to keep the consistency of feedback provision.

\section{Data Collection}

The following data were collected: audio- and video- data, and students' generated and revised free body diagrams. The audio data was used for transcription purpose; and the video data was used to capture participants construction of diagrams and how they refined their diagrams as a result of question asking. Camera angle focused on what participants drawing and efforts was made to not show their face.

\section{Data Analysis}

The resulting think-aloud protocols were transcribed verbatim. To ensure the validity of the research, the authors took different lens to code the data ${ }^{[38]}$. In the first round, the authors analyzed students' responses and constructed a profile of each participant's conceptions of buoyancy. Furthermore, the authors aggregated similarities in responses to each question, and started the second round of coding. The authors used open coding to categorize all the responses to the same research question based on patterns, similarities and differences. By doing this, the authors want to capture "meta" statements that indicate participants' interpretations of both the content knowledge (system equilibrium) and the tool knowledge (free body diagrams).

Another emphasis of data analysis to identify students' stances on the use of PPDs. Judgments about students reasoning with PPDs were derived from examining interview transcripts. To start with, responses that shed light on interpreting, evaluating, criticizing, and comparing with PPDs were identified. Themes emerged from the data and were categorized with further explanation and quotations from the transcripts as examples.

Validity and Reliability

It is challenging to ensure the validity of qualitative research ${ }^{\text {[38], [39] }}$. Validity was defined as "how accurately the account represents participants' realities of the social phenomena and is credible to them" ${ }^{[38], ~[40]}$ Creswell and Miller suggest two perspective s to govern the validity in qualitative inquiry: the lens chosen by researchers to validate their studies and researchers' paradigm assumptions ${ }^{[38]}$. In this paper, the authors took difference lens to code the data to ensure the validity of the study, i.e. creating profiles for each participant and aggregating responses by research questions. 
The reliability of qualitative research refers to the degree to which a test consistently measures whatever it measures ${ }^{[39]}$. To establish the intra-rater reliability of the coding, the protocols were single-coded twice on different days that are 14 days apart by the authors.

\section{Results}

This scenario required unpacking the systems and reasoning with the dynamic equilibrium. The answers could not be obtained by simply retrieving the declarative knowledge of buoyancy. Therefore, generating diagram is assumed to be a powerful tool during the problem solving process.

To answer correctly, students' free body diagrams should include a downward force of gravity balanced by an upward buoyant force, the tension from the fishing hook and the force from the water flow before the thread is cut. There were eleven (out of fourteen) accurate diagrams. As illustrated in Table One, two students missed the existence of force from the water flow and another one missed the existence of the gravity. When students were asked to predict how the float would move after the tread is cut, ten students mentioned "up and right" and provided the right justifications to their answers. The two students who missed the existence of the force from the water flow incorrectly predicted the movement of the float by answering "up". During their explanations, they referred to their initial incomplete diagram to look for answers; therefore they might easily overlook the force from the water flow and get the wrong answer. One student who generated the correct free body diagram indicated the float would go upwards because tension from the fishing hook and the force from the water flow canceled out each other and the buoyancy made the float rise. Interestingly, another student who also generated the correct free body diagram indicated the float would go right because the buoyancy and the gravity canceled out each other and the force from the water flow made the float go right. Inabilities to use diagrams to further justify the answers are one potential cause of the failed predications. It may be challenging for students to handle more than one variable and simplify the situation.

When asking about if there is change of the buoyancy acting on the float during the movement, inaccurate and partially accurate responses ranged from stating that the buoyant force kept increasing, to mentioning that the buoyant force kept decreasing , to believing that there was no change to the buoyant force. Four out of fourteen students were able to relate the magnitude of the buoyant force to the weight of the displaced water, and correctly identified the change of the buoyancy as $\mathrm{Fa}=\mathrm{Fb}>\mathrm{Fc}$. Partially accurate responses were from students who were able to analyzing the determining factors of buoyancy, but failed to recognize fishing float was partially submerged at point $\mathrm{c}$ and the volume of the displaced water is less at point $\mathrm{c}$ than point a. Therefore, they $(\mathrm{N}=5)$ believed there was no change on buoyancy during the movement. Four students indicated the buoyancy kept decreasing due to the decreasing of the liquid density. These students could attribute the magnitude of the buoyant force to the density of the liquid, but failed to consider another determining factor, i.e., the volume of displaced liquid. There was one student who believed the buoyant force kept increasing because there was less water pushing down as the float went up. It seems that this student would want to 
consider another variable for the system equilibrium, but could not recognize the determined factors of the buoyancy per se.

Table One, Students’ Responses to The Fishing Float System

\begin{tabular}{|c|c|c|c|c|c|c|c|c|c|}
\hline \multirow[t]{3}{*}{ No. } & \multicolumn{9}{|c|}{ Fishing Float System } \\
\hline & \multicolumn{2}{|c|}{$\begin{array}{l}\text { Identifications } \\
\text { of Forces }\end{array}$} & \multicolumn{3}{|c|}{$\begin{array}{l}\text { Predication of the } \\
\text { movement }\end{array}$} & \multicolumn{4}{|c|}{ Change of Buoyancy } \\
\hline & Four* & Three & $\begin{array}{l}\text { Up \& } \\
\text { right* }\end{array}$ & Up & Right & $\mathrm{Fa}=\mathrm{Fb}>\mathrm{Fc}^{*}$ & $\mathrm{Fa}=\mathrm{Fb}=\mathrm{Fc}$ & $\mathrm{Fa}>\mathrm{Fb}>\mathrm{Fc}$ & $\mathrm{Fa}<\mathrm{Fb}<\mathrm{Fc}$ \\
\hline 1 & $\mathrm{X}$ & & $X$ & & & & $X$ & & \\
\hline 2 & X & & X & & & & & $X$ & \\
\hline 3 & X & & X & & & & & $X$ & \\
\hline 4 & X & & X & & & & & & X \\
\hline 5 & $X$ & & X & & & X & & & \\
\hline 6 & X & & X & & & & X & & \\
\hline 7 & X & & X & & & X & & & \\
\hline 8 & X & & & & X & X & & & \\
\hline 9 & X & & X & & & & & $X$ & \\
\hline 10 & X & & $X$ & & & & & $X$ & \\
\hline 11 & & $\mathrm{x}(\mathrm{w})$ & & $X$ & & X & & & \\
\hline 12 & & X(g) & X & & & & X & & \\
\hline 13 & & $\mathrm{X}(\mathrm{w})$ & & $X$ & & & X & & \\
\hline 14 & X & & & $X$ & & & X & & \\
\hline
\end{tabular}

Two PPDs were provided afterwards and an intended mistake was included in the normal peer diagram. As illustrated in Figure Two, this mistake was to use buoyancy to counterbalance the force of tension.
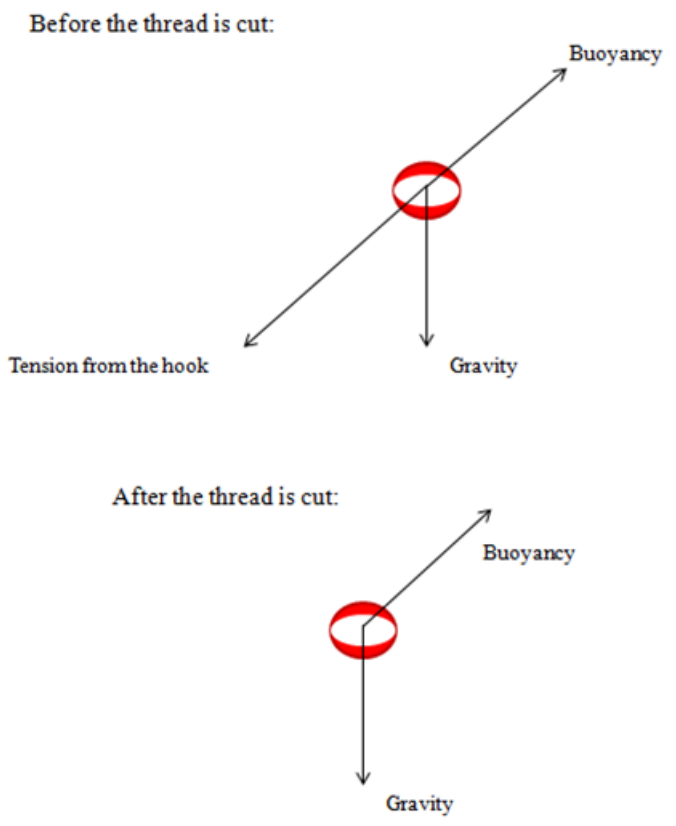

Figure Two, Normal Peer Diagram 
To identify the mistake, students need to know that the direction of the buoyancy is always going upwards. As illustrated in Table Two, half of the students considered the force as the combined force from the water. For example, one student mentioned that " $I$ assume he just added the contribution the buoyant force and the force from the water". Some students even further justify their answers as following, "I would think to combine the buoyancy and the normal force from the water to one force is not right. Because the force from the flow is not dependant on the same things as the buoyancy does"

Table Two, Students’ Responses to the Normal Peer Diagram

Fishing Float System - Normal Peer Diagram

\footnotetext{
Themes

Examples

TC: Treat the wrong force as the combined force

No. 1: I assume he just added the contribution the buoyant force and the force from the water;

No. 8: It looks like they incorporated the buoyant force and the drag force, they combined them into one.

No. 10: It seems that they combined the force from the water pushing this way and the buoyancy into one force here

CM: Correct the Mistake

No. 3: The buoyancy should only have the vertical component. they also forgot the water flow, which has impact on the ball

No. 7- . So before the thread is cut, the students neglected to take the force from the water, and the buoyancy should always go directly upward. That is the main difference I would like to correct.

No. 14: I think they are wrong; they need to think about the direction of the buoyancy.

F: Finding No. 12: Oh, I forgot the gravity.

mistakes

Match: Match

the initial

No.4: the first one, before the thread is cut, this matches my tension force; gravity is like mine because it is going straight down to the earth

thinking

P: Predict the conclusion that

No. 1: I mean the conclusion might be the water all acting on the same direction?

the peer tried to

make

Twelve students could correct the mistake in the normal peer diagram and provided justifications for their answers. Some of them compared the normal peer diagram with their own diagram and pointed out the mistake. One student even tried to predict what kind of conclusions that the normal peer would make. Others retrieved their prior knowledge and stated that the buoyant force only has the vertical component. When comparing their work with the normal peer diagram, one student reported the mistake in his or her initial diagram; another student mentioned that the normal peer diagram matched his or her own diagram and confirmed their initial thinking.
} 


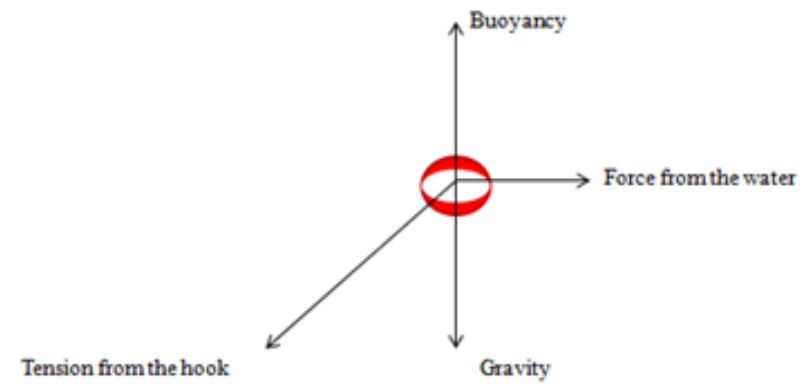

After the thread is cut:

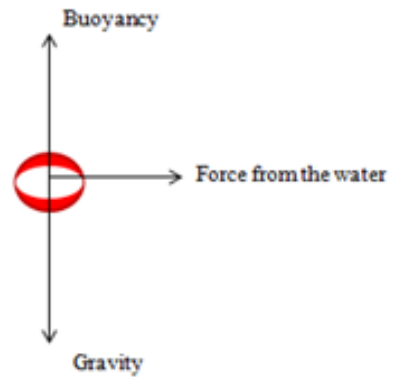

Figure Three, Super Peer Diagram

After students reviewed the normal peer diagram, the authors provided the super peer diagram (see Figure Three) for students to compare and contrast with.

Table Three, Students’ Responses to the Super Peer Diagram

Fishing Float System - Super Peer Diagram

\begin{tabular}{ll}
\hline Themes & Examples \\
\hline $\begin{array}{l}\text { CD: Conventions } \\
\text { of free body }\end{array}$ & $\begin{array}{l}\text { No.1: Agree with this diagrams except for the convention of the BFD( Pulling or } \\
\text { Pushing?) }\end{array}$ \\
& $\begin{array}{l}\text { No. 3: but the lines should be proportional to the force } \\
\text { No. 7: An important difference here is the buoyancy is not greater than the gravity, so } \\
\text { there will be negative force here which does not make sense because we know we are } \\
\text { in the static equilibrium. }\end{array}$ \\
& $\begin{array}{l}\text { No. 10: This is similar to mine. This is correct. } \\
\text { M: Match the }\end{array}$ \\
initial thinking & No. 14 this one is the same as mine. I didn't notice any differences. \\
MM: Mismatch & No. 11: they think there is a drag force from the water, which I would not agree. The \\
the initial thinking & water force would work equally on all the sides of the ball.
\end{tabular}

As illustrated in Table Three, three students discussed the convention of free body diagrams used in the super peer diagram. Their main comments include the position of the arrow lines and the length of the arrow lines. One student could not determine if the force from the water flow was pulling force or pushing force. Another two students 
indicated that the arrow lines should be proportional to the magnitude of the force. Half students mentioned that the super peer diagram matched their initial thinking and could not notice any differences. There was one student who did not agree with the super peer diagram. As illustrated in his or her free body diagram, he or she believed that the water force would work equally on all the sides of the float.

\section{Discussion}

In general, a majority of students were able to identify the correct answers and to demonstrate coherent reasoning process when approaching the phenomena of buoyancy. PPDs served as a powerful tool to provide formative feedback and to elicit students' thinking. The majority of the students had the "Ah-ha" moment when they reviewed the super peer diagram, and applied what they learned from the expert diagram to correct their own diagram and the normal peer diagram. They admitted that some PPDs confirmed their initial thinking. They were active in comparing and contrasting their work with the given PPDs, and tried to discover the "match" and the "mismatch" between diagrams. Some students even tried to stand in the peers' shoes and predicted what conclusions the peers were trying to make and provided suggestions for the peers.

\section{Conclusion}

This study illustrates the pedagogical affordances of asking students to compare and contrast their work with given models. The results not only revealed the challenges that students have when they interpret buoyancy, but also indicated how powerful PPDs are as the avenue of providing formative assessment. Our further work will focus on more complex problems to increase students' proficiency with these construction skills and to develop the abstract conceptual understanding they will need to manage complex tasks. We seek to have a richer description of how students approach these problems and the kinds of challenges they experience as they work on these problems.

Another interesting direction for the future work is to remove blind spots from super peer diagrams to increase its expressiveness to notice governing principles and details. The role of equations could be examined to see whether students could perform better by interpreting additional mathematical justifications. The author conjectures that, different from the static pre-designed PPDs, the step-by-step modeling process may provide more scaffolding to students in the problem-solving process. To further examine the effectiveness of PPDs, a controlled group could be included in the future studies. It is also interesting to employ the findings of this study is on transfer tasks, i.e., to use PPDs as the interventions to promote students' abilities to engage in adaptive, flexible transfer. Though such abilities require time and practice, it is meaningful to provide multiple perspectives as one major training approach and the avenue of formative assessment.

This research is relevant to engineering instructors and researchers who want to develop students' abilities to use cognitive strategies effectively. It may also interest engineering 
instructors who are willing to apply new instructional methods and tools to facilitate students to overcome complex design challenges.

\section{Acknowledgements}

This research was made possible with a grant from the National Science Foundation (Award Number - DUE-0817486)

Bibliography

[1] Black, P., \& Wiliam, D. (1998a). Assessment and classroom learning. Assessment in Education: Principles Policy and Practice, 5(1), 7-73.

[2] Bransford, J.D., Brown, A. L., \& Cocking, R. R. (2000). How People Learn: Brain, Mind, Experience, and School: Expanded Edition. Washington, DC: The National Academies Press.

[3] Orsmond, P., Merry, S. \& Relling, K. (2002). The use of exemplars and formative feedback when using student derived marking criteria in peer and self assessment, Assessment and Evaluation in Higher Education, 27(4), 309-323.

[4] Black, P., \& Wiliam, D. (1998b). Inside the black box: Raising standards through classroom assessment. Phi Delta Kappan, 80(2), 139-147.

[5] Heritage, M. (2010). Formative assessment and next-generation assessment systems: Are we losing an opportunity? A project of Margaret Heritage and the Council of Chief State School Officers. Washington, DC: Council of Chief State School Officers.

[6] Sadler, D. R. (1998). Formative assessment: revisiting the territory. Assessment in Education, 5(1), 7784.

[7] Clariana, R. B. (1990). A comparison of answer-until-correct feedback and knowledge of-correct response feedback under two conditions of contextualization. Journal of Computer-Based Instruction, 17(4), 125-129.

[8] Moreno, R., \& Mayer, R. E. (2007). Interactive multimodal learning environments. Educational Psychology Review, 19(3), 309-326.

[9] Hattie, J., \& Timperley, H. (2007). The power of feedback. Review of Educational Research, 77 (1),81112.

[10] Chi, M. T. H. (2001). Self-explaining: The dual processes of generating inferences and repairing mental models. In Advances in instructional psychology: Educational design and cognitive science, ed. R. Glaser, 161-238. Mahwah, NJ: Erlbaum.

[11] Moreno, R., \& Valdez, F. (2005). Cognitive load and learning effects of having students organize pictures and words in multimedia environments: The role of student interactivity and feedback.

Educational Technology Research and Development 53(3), 35-45.

[12] Vygotsky, L.S. (1978). Mind and society: The development of higher mental processes. Cambridge, MA: Harvard University Press.

[13] Taras, M. (2001). The use of tutor feedback and student self-assessment in summative assessment: towards transparency for students and for tutors. Assessment and Evaluation in Higher Education, 26(6), 605-614.

[14] Hmelo-Silver, C. E. \& Barrows, H. S. (2006). Goals and strategies of a problem-based learning facilitator. Interdisciplinary Journal of Problem-based Learning, 1(1), 21-39.

[15] Roselli, R. J., \& Brophy, S. P. (2006). Experiences with formative assessment in engineering classrooms. Journal of Engineering Education, 95 (4), 325-333. 
[16] Biesta, G .(2004). Mind the gap! Communication and the educational relation. In Bingham, C., \& Sidorkin, A .eds. No Education without relation. New York: Peter Lang.

[17] Brophy, S. P., Klein, S., Portsmore, M., \& Rogers, C. (2008). Advancing engineering education in the P-12 classrooms. Journal of Engineering Education, 97 (3), 369-387.

[18] Johri, A. \& Lohani, V. (2008). Representational Literacy and Participatory Learning in Large Engineering Classes Using Pen-Based Computing. Proceedings of the 38th ASEE/IEEE Frontiers in Education Conference, Saratoga Springs, NY.

[19] Gieskes, K., DeRusso, C., \& McGrann, R. (2012). Visual Representations in Mechanical Engineering Education. Proceedings of the 2012 American Society of Engineering Education Annual Conference \& Exposition, San Antonio, TX.

[20] Tversky, B. (2005). Visuospatial reasoning. In K. Holyoak \& R. Morrison (Eds.), The Cambridge handbook of thinking and reasoning. Cambridge, MA: Cambridge University Press.

[21] Zumbach, J., Reimann, P., \& Koch, S. C. (2006). Monitoring students' collaboration in computermediated collaborative problem-solving: Applied feedback approaches. Journal of Educational Computing Research, 35(4), 399-424.

[22] Spivey, N. N. (1991). The shaping of meaning: Options in writing the comparison. Research in the Teaching of English, 25, 390-418.

[23] Smith, F. (1971). Understanding Reading. New York: Holt, Rinehart and Winston.

[24] Sitko, B. M. (1998). Knowing how to write: Metacognition and writing instruction. In D. J. Hacker, J.

Donlosky, \& A. C. Graesser (Eds.), Metacognition in educational theory and practice (pp. 93-115).

Mahwah, NJ: Erlbaum.

[25] Dickson, S. V., Simmons, D., \& Kameenui, E. J. (1995). Instruction in expository text: A focus on compare/contrast structure. LD Forum, 20, 8-15. Council for Learning Disabilities.

[26] Raphael, T. E., \& Englert, C. S. (1990). Writing and reading: Partners in constructing meaning. The Reading Teacher, 43, 388-400.

[27] Prosser, M. \& Trigwell, K. (1999). Understanding learning and teaching. The experience in higher education. Buckingham, Open University Press.

[28] Brophy, S. P. \& Li, S. (2010). A framework for using graphical representations as assessment of engineering thinking. Proceedings of the 2010 American Society of Engineering Education Annual Conference \& Exposition, Louisville, KY.

[29] National Research Council (NRC). (2001). Knowing what students know. Washington, DC: National Academies Press.

[30] Streveler, R. A., Litzinger, T. A., Miller, R. L., \& Steif, P. S. (2008). Learning conceptual knowledge in the engineering sciences: Overview and future research directions. Journal of Engineering Education, 97(3), 279-294.

[31] Chi, M. T. H. (2005). Commonsense conceptions of emergent processes: Why some misconceptions are robust. Journal of the Learning Sciences, 14(2), 161-199.

[32] Minstrell, J., Kraus, P., \& Madhyastha, T. (2007). Facets and Facet Clusters and A Theoretical

Backdrop for Designing Assessment Items. Paper presented at the National Council on Measurement in

Education, Chicago, Illinois.

[33] Yin, Y., Tomita, M. K., \& Schavelson, R. J. (2008). Diagnosing and Dealing with Student

Misconceptions: Floating and Sinking. Science Scope, 31(8), 34-39.

[34] Kariotogloy, P., Koumaras, P., \& Psillos, D. (1993). A constructivist approach for teaching fluid phenomena. Physics Education, 28,164-169.

[35] Hibbeler, R. C. (1995). Engineering Mechanics: Statics and Dynamics. Prentice-Hall, Englewood

Cliffs, N.J.

[36] Roselli, R. J., Howard, L. \& Brophy, S. P. (2006). A computer-based free body diagram assistant.

Computer Applications in Engineering Education. 14(4), 281-290.

[37] Steif, P. S., Lobue, J., Fay, A. L., Kara, L. B., \& Spencer, S. E. (2007). Inducing students to contemplate concept-eliciting questions and the effect on problem solving performance, Proceedings of the

37th American Society for Engineering Education Annual Conference \& Exposition, Honolulu, HI.

[38] Creswell, J. \& Miller, D. (2000). Determining validity in qualitative inquiry. Theories Into Practice, 39(3), 124-130.

[39] Patton, M.Q. (1980). Qualitative evaluation methods. Newbury Park, CA: Sage.

[40] Schwandt, T.A. (1997). Qualitative inquiry: A dictionary of terms. Thousand Oaks, CA: Sage. 


\section{Appendix. Information Sheet}

What is buoyancy?

- In physics, buoyancy is an upward force exerted by a liquid, gas or other fluid that opposes the weight of an immersed object. In a column of fluid, pressure increases with depth as a result of the weight of the overlying fluid. Thus a column of fluid, or an object submerged in the fluid, experiences greater pressure at the bottom of the column than at the top. This difference in pressure results in a net force that tends to accelerate an object upwards. The magnitude of that force is proportional to the difference in the pressure between the top and the bottom of the column, and (as explained by Archimedes' principle) is also equivalent to the weight of the fluid that would otherwise occupy the column, i.e. the displaced fluid. For this reason, an object whose density is greater than that of the fluid in which it is submerged tends to sink.

- Any object, wholly or partially immersed in a fluid, is buoyed up by a force equal to the weight of the fluid displaced by the object.

- Archimedes of Syracuse

- Formula for Buoyant Force:

$\mathrm{F}$ (buoyant) $=\mathrm{pVg}$

$$
\begin{aligned}
& \mathrm{p}=\text { density of the fluid } \\
& \mathrm{V}=\text { volume of the object being submerged } \\
& \mathrm{g}=\text { standard gravity on Earth }(\sim 9.81 \mathrm{~N} / \mathrm{kg})
\end{aligned}
$$

Reference

http://en.wikipedia.org/wiki/Buovancy 